O "GRUPO DA PRESSÃC NOTAS SOBRE AS LÓGICAS "CONTROLE" DE DOEN
CRÔNICAS NA GUARIR CEILÂNDIA 


\section{O "GRUPO DA PRESSÃO”: NOTAS SOBRE AS LÓGICAS DE "CONTROLE" DE DOENÇAS CRÔNICAS NA GUARIROBA, CEILÂNDIA/DF}

\section{SORAYA FLEISCHER}

UNIVERSIDADE DE BRASÍLIA, BRASIL 


\title{
O "GRUPO DA PRESSÃO": NOTAS SOBRE AS LÓGICAS DO "CONTROLE" DE DOENÇAS CRÔNICAS NA GUARIROBA, CEILÂNDIA/DF
}

\section{Resumo}

A Antropologia brasileira tem priorizado vagarosamente o tema das doenças crônicas e degenerativas. Doenças como a hipertensão arterial sistêmica e a diabetes mellitus tipo 1 e tipo 2, por exemplo, que têm um impacto epidemiológico inegável na população brasileira, recebem aportes analíticos das áreas da saúde, mas só nos últimos anos têm captado a atenção dos pesquisadores das Ciências Sociais. As áreas da saúde, que por enquanto não oferecem curas definitivas para essas doenças, têm consolidado práticas de "controle" como formas de tratamento. Sobre essas práticas de controle é que repousa o foco desse artigo, sobretudo aquelas elaboradas pelas pessoas que vivem com essas doenças. Primeiro, apresento os passos metodológicos em campo. Depois, discuto três grandes conjuntos de práticas de controle realizadas por pessoas que convivem com hipertensão arterial e/ou diabetes mellitus no bairro da Guariroba, Distrito Federal. Medir os índices corporais e conhecer a própria "normalidade"; ter vários aparelhos de medir à mão; discutir os números enunciados pelos aparelhos com um público amplo e diverso; reinventar a posologia dos medicamentos; e conhecer a influência das emoções nestas doenças crônicas são as práticas que considero terem intuito controlador para os entrevistados nessa pesquisa. Por fim, anuncio possibilidades interpretativas como um aporte provisório para fazer avançar os estudos sobre a cronicidade na Antropologia brasileira.

Palavras-chave: Doenças crônicas, práticas de controle, Guariroba (Distrito Federal).

\section{THE "PRESSURE GROUP": NOTES ON THE LOGIC OF "CONTROL” OF LONG-TERM ILLNESSES IN GUARIROBA, CEILÂNDIA/DF}

\begin{abstract}
Brazilian Anthropology has only slowly given priority to the theme of chronic and degenerative illnesses. Hypertension and diabetes mellitus, type I and II, for example, with a massive epidemiological impact on the Brazilian population, are analytically tackled by health studies, but only in the last years have they captured the Social Sciences' attention. The health areas, meanwhile, cannot offer definite cure for theses illnesses, and have elaborated "control" practices as forms of treatment. This article intends to focus on these control practices, especially those elaborated by people that live with these illnesses. First, I present the methodological steps. Then, I discuss three sets of practices put to work by Guariroba (Federal District) dwellers interviewed in the research. Measure the body indicators and acknowledge one's own "normality"; have many measuring equipment at hand; discuss the numbers with a large
\end{abstract}


and diverse audience; reinvent the medicine posology; and get to know the influence of emotions on these two illnesses are practices that seem to have a strong control intention to these interviewees. Finally, I announce interpretations that temporarily serve to help advance the studies on chronicity in the Brazilian Anthropology.

Key words: Chronic illness, control practices, Guariroba (Federal District).

\section{EL "GRUPO DE PRESIÓN": NOTAS SOBRE LAS LÓGICAS DEL “CONTROL" DE ENFERMEDADES DE LARGA DURACIÓN EN GUARIROBA, CEILANDIA/DF}

\section{Resumen}

La Antropología brasileña ha priorizado lentamente el tema de las "enfermedades crónicas y degenerativas". Enfermedades como la hipertensión arterial sistémica y la diabetes mellitus tipo 1 y tipo 2, por ejemplo, cuyo impacto epidemiológico es innegable en la población brasileña, reciben aportes analíticos de las áreas de la salud y sólo en los últimos años han captado la atención de los investigadores de las Ciencias Sociales. Las áreas de la salud, que por ahora no ofrecen curaciones definitivas para estas enfermedades, han consolidado prácticas de "control" como formas de tratamiento para dichas dolencias. El foco de este artículo reposa sobre esas prácticas de control, en especial aquellas que son elaboradas por las personas que viven con estas enfermedades. Primero, presento los pasos metodológicos en campo, y después, discuto tres grandes conjuntos de prácticas de control realizadas por personas que conviven con hipertensión arterial y/o diabetes mellitus en el barrio Guariroba, Ceilandia/ Distrito Federal. Considero que, para estos entrevistados, las prácticas que tienen la intención controladora sobre las enfermedades en cuestión son: medir los índices corporales y conocer la propia "normalidad", accionar varios aparatos para medir, discutir los números enunciados por los aparatos con un público amplio y diverso, reinventar la posología de los medicamentos, y, conocer la influencia de las emociones en estas enfermedades crónicas. Finalmente, señalo algunas posibilidades interpretativas como un aporte para hacer avanzar los estudios sobre la cronicidad en la Antropología brasileña.

Palabras-clave: Enfermedades de larga duración, control, Ceilândia (Distrito Federal).

Endereço da autora para correspondência: Departamento de Antropologia. Campus Universitário Darcy Ribeiro, ICC Centro, Sobreloja, B1 347. Brasília, DF 70910-900.E-mail: fleischer.soraya@gmail.com 


\section{OS ESTUDOS DA “CRONICIDADE”}

A Antropologia brasileira tem priorizado vagarosamente o tema das doenças crônicas e degenerativas, sobretudo em comparação com a Sociologia britânica (Bury 1982) e estadunidense (Corbin \& Strauss 1985; Becker 1997). Desde a década de 1970, os sociólogos têm estudado como é conviver com uma doença que não recebe, por parte da biomedicina, uma cura definitiva. Contudo, doenças como a hipertensão arterial sistêmica e a diabetes mellitus tipo 1 e tipo 2, por exemplo, que têm um impacto epidemiológico inegável na população brasileira, recebem aportes analíticos das áreas da saúde, mas só nos últimos anos têm captado a atenção dos pesquisadores das Ciências Sociais (Leibing \& Groisman 2004; Canesqui 2007; Souza \& Garnelo 2008; Calvo-Gonzalez 2011). Há poucos anos, 35\% dos brasileiros com mais de 40 anos, haviam sido diagnosticados com hipertensão (IBGE 2004) e quase $8 \%$, na mesma faixa etária, para manter os termos de comparação, com diabetes (Vigitel 2008).

Por bastante tempo, na Sociologia, a ideia de Parsons (1951) de "sick role" foi aceita e reproduzida. No entanto, os estudos sobre as doenças crônicas demonstraram que esse conceito foi principalmente cunhado para as doenças agudas, já que a pessoa manteria o papel de doente enquanto estivesse sob tratamento. As doenças vitalícias, como é o caso da cronicidade, demandam conceitos que deem conta do contato clínico como mais uma das etapas vivenciadas e não como a experiência mais importante e norteadora, como pareceu nos sugerir Parsons. Dessa forma, não é possível considerarmos as pessoas como "pacientes" em tempo integral e, mesmo nos espaços hospitalares, é preciso observar se de fato se percebem como "pacientes". Pensar nos limites do conceito parsoniano, ao desinstitucionalizar a doença e explodir o "estado de paciente" (patienthood) de uma pessoa adoentada, nos leva a atentar para a autonomia e agência dessa pessoa de uma forma geral, escolhendo o próprio itinerário terapêutico, medicamentos, cuidadores e curadores etc.

Em vez do "medicocentrismo" do conceito parsoniano, vários autores sugerem que nos voltemos à perspectiva dos adoecidos que "vivem com e apesar da doença” (Conrad 1990). Os estudos realizados por Anselm Strauss foram os primeiros a desestabilizar a hegemonia teórica parsoniana. "The focus of [his] study would be the subjective experience of being ill and how people managed their illness. They moved from studying patients to studying how people experienced and lived their illness in everyday life" (Conrad \& Bury 1997: 374, grifos meus).

Assim, pelo fato de ter que conviver com uma patologia por décadas a fio, estas pessoas têm a oportunidade de refletir sobre essa experiência de várias formas e em vários momentos, tornando-se parceiros ideais ao antropólogo em campo, já que se transformam em profundos conhecedores da própria experiência. No caso das pessoas que tenho conhecido nessa pesquisa, embora eu perceba esforços criativos de 
manejo da doença e manutenção da autonomia, não se pode perder de vista os encontros clínicos que, pelo modelo biomédico proporcionado, acontecem com bastante frequência. Não mantêm o "sick role" em tempo integral, isso está claro, mas por vezes o encarnam, sobretudo ao se depararem com as práticas de "controle" instituídas pelas equipes de saúde ou com a necessidade de desenhar táticas para circular melhor pelas instituições no exercício de seus direitos. Sobre essas práticas de controle é que desejo repousar o foco desse artigo, sobretudo as práticas elaboradas pelas pessoas que vivem com essas doenças. Vale ressaltar que meus interlocutores, por vezes, se inspiram nas práticas de controle enunciadas pelo centro de saúde; por vezes, criam suas próprias formas de acompanhar as doenças e suas flutuações. $\mathrm{O}$ importante é ressaltar que nesse caso nem sempre estão em franco antagonismo, crítica ou confronto com as práticas oficiais. Focar nos pacientes e seus cotidianos não quer dizer que eu esteja me antepondo ou ignorando as iniciativas governamentais para dar conta dessas doenças crônicas. Não pretendo qualquer efeito maniqueísta, apenas trazer à tona como essas pessoas têm lidado com os inconvenientes da hipertensão e da diabetes em seu dia a dia, já que essa perspectiva - aquela em primeira pessoa - tem sido pouco visibilizada quando se trata de políticas de saúde do HIPERDIA.

A partir de políticas federais, como o Hiperdia por exemplo, ${ }^{1}$ que são capilarizadas em nível municipal e distrital, doenças como a hipertensão e a diabetes são dirigidas à atenção básica de saúde. No Centro de Saúde onde tenho pesquisado, há o que denomino de um "circuito clínico". O primeiro contato com um centro de saúde acontece pelo "balcão de atendimento", que orientará a pessoa à "sala de acolhimento". Ali, técnicas em enfermagem aferem os índices corporais e, quando há necessidade e também vaga, encaminham a pessoa ao "grupo de apoio". Cada "grupo" abriga cerca de 20 pessoas, que aí se mantêm até que eventualmente faleçam, mudem de residência ou decidam abandonar o tratamento. O "grupo" começa por volta das $7 \mathrm{~h} 30$, quando as pessoas se dirigem à sala de reuniões da instituição. A equipe responsável chega um pouco depois, já com os prontuários daquele conjunto de pacientes. $^{2}$ As pessoas têm, então, sua pressão sanguínea e/ ou glicose aferida e anunciada em voz alta e clara, uma a uma, na parte da frente da sala. Essas informações são anotadas nos prontuários que depois são organizados por ordem de chegada e de idade das pessoas. ${ }^{3}$ Os prontuários são, então, entregues ao clínico que estiver atendendo naquele dia. Ele chama a primeira pessoa da fila que, na saída do consultório, já chama a seguinte. Depois da consulta, as pessoas geralmente seguem à farmácia do Centro de Saúde, para a retirada dos medicamentos de costume. Esse ritualizado "circuito clínico" acontece a cada trimestre e a cada quadrimestre no caso das pessoas com diabetes e hipertensão, respectivamente, e deve ser seguido à risca como condição para receber tratamento e alcançar os 
medicamentos. Por esse último motivo é que, como se verá abaixo, meus dados revelam como a participação nos "Grupos" é meramente instrumental, desviando bastante do intuito de "ajuda-mútua" esperada pelo Hiperdia ou de alguma espécie de "apoio", como teoricamente desejaria o Centro, inclusive ao nomeá-lo como tal.

Em todas as etapas do "circuito clínico", percebo estratégias bastante evidentes e planejadas de controle, como comentei alhures:

"Avento que a cronicidade, identificada entre os pacientes com quadros de hipertensão arterial e diabetes mellitus, é a primeira condição que precisa lhes ser atribuída para, num segundo momento, operar um severo controle de cada um de seus passos, seja em termos de presença nas consultas, uso de medicamentos, seguimento de dietas alimentares e de exercícios etc. E esse controle é o principal serviço oferecido pelo Centro de Saúde aos pacientes "de cartão", como os pacientes "crônicos" são aí conhecidos. A cronicidade e o controle são duas faces da mesma moeda, ao se definir o primeiro, se implica em colocar o segundo na prática. Um é rótulo, o outro é esse rótulo em ação.” (Fleischer 2010: 4)

O "controle" é exercido e comunicado em várias instâncias do "circuito" e por vários atores, dos mais aos menos hierárquicos. Pontualidade nas reuniões do "grupo", manutenção dos índices corporais conforme os protocolos clínicos, obediência às prescrições feitas nos consultórios, re- tirada e consumo integral dos medicamentos indicados são todos exemplos do controle dos comportamentos, altamente valorizado pela equipe de médicos, enfermeiras, farmacêuticos, atendentes de enfermagem, nutricionistas, assistentes sociais e até os vigilantes de portaria. Nem sempre, como as pessoas têm me mostrado, seguir a cartilha biomédica rende resultados positivos em termos de uma boa saúde ou de índices sanguíneos ideais. Elas têm me mostrado que não discordam que o "controle" seja uma ferramenta para se conviver diariamente com doenças que precisam de manejo continuado. Mais importante, a meu ver, é como se apropriam da ideia de "controle" e inventam formas distintas para colocála em prática. É essa perspectiva que me proponho a descrever e analisar abaixo. Primeiro, apresento meus passos metodológicos em campo. Depois, discuto três grandes conjuntos de práticas de controle realizadas por estas pessoas que convivem com hipertensão arterial e/ou diabetes mellitus. Tenho tentado evitar chamar estas pessoas simplesmente de "hipertensas" ou "diabéticas", como vejo ser feito com naturalidade pelos espaços terapêuticos onde circulo. Se a categoria parsoniana de "sick role" não me satisfaz, é preciso lembrar que essas pessoas são muito mais do que portadoras de uma doença e, por isso, exercito-me em desgrudá-las dessa alcunha encompassadora. Por fim, anuncio possibilidades interpretativas apenas como um aporte provisório e modesto para fazer avançar os estudos sobre a cronicidade na antropologia brasileira. 


\section{PASSOS METODOLÓGICOS}

Desde 2008, tenho frequentado a Guariroba com intuitos de pesquisa etnográfica sobre cronicidade entre camadas populares (ver Fleischer 2012a e 2012b; Fleischer 2012c; Fleischer et al, 2012). Este é um dos bairros da Ceilândia, maior cidade do Distrito Federal. A Ceilândia guarda uma história sofrida no quadro da capital, a começar pelo nome com o qual foi batizada, que contém o estigma que lhe deu origem. "CEI" equivale a "Centro de Erradicação de Invasões”, já que quase 80 mil pessoas, geralmente vindas dos estados do Nordeste e também de Goiás e Minas Gerais, foram arbitrariamente desalojadas de seus acampamentos e vilas no espaço da capital federal e transferidas de forma compulsória para o "meio do mato", como era percebido naquele início dos anos 1970 o espaço ermo e $35 \mathrm{~km}$ distante da capital (Resende 1985). Permitiu-se que levassem seus materiais de construção originais e as primeiras habitações na Ceilândia também foram barracos improvisados. Só mais tarde, com a criação da SHIS, ${ }^{4}$ é que as primeiras e modestas casas subsidiadas pelo Estado foram entregues, justamente no bairro da Guariroba.

Assim, tenho insistido em conhecer um pouco dessas quase quatro décadas de história do bairro, na esperança de encontrar pontos de convergência entre as biografias e os cuidados com a saúde, meu tema mais amplo de pesquisa. As pessoas com quem tenho mantido contato mais extenso estão todas na casa dos 60, 70 e 80 anos de idade e vivenciaram situações de migração para o DF, remoção de Brasília e criação da Guariroba. Envelhecer é também ver a cidade se transformar, a "violência" grudar na Ceilândia como um novo estigma (Tavares 2012), ver muros e portões se erguerem e perceber a saúde ser acometida de forma perene, como é o caso das patologias crônicas.

Embora tenho pesquisado nessa região desde 2008, para este artigo irei me concentrar nos dados do período de 2011. Meu acesso às pessoas que convivem com essas doenças crônicas se dá a partir da presença em um Centro de Saúde do bairro, que tem aceitado e abrigado nossas iniciativas de pesquisa e extensão desde o início. O "Centro de Saúde", chamado em outras regiões do país de "Unidade Básica de Saúde", é conhecido no bairro como "centro", "posto de saúde" ou simplesmente "postinho". Além disso, me beneficio de uma rede de estudantes da UnB que vivem na Guariroba e, de forma muito gentil, tem se prestado a me apresentar vizinhos, parentes e conhecidos no bairro. ${ }^{5}$ Para esse artigo, considero um universo de 16 pessoas que conheci, mais especificamente da primeira forma, nos bancos onde ficam a esperar pelos atendimentos no Centro de Saúde. Em geral, as mulheres são trabalhadoras domésticas (diaristas, mensalistas, passadeiras, lavadeiras), costureiras e donas de casa, ao passo que os homens trabalham como pedreiros, eletricistas, porteiros, taxistas e motoristas. Mas já na fase da vida em que se encontram, estas mulheres continuam com as tare- 
fas de cuidado da própria casa, mas não mais das casas alheias. Assim também, os homens geralmente estão aposentados, salvo os que não conseguiram a segurança de terem sido "fichados" e ainda hoje trabalham como autônomos. Essas 16 pessoas são migrantes nordestinos que vivem, atualmente, em "casas da SHIS", que já foram bastante modificadas e incrementadas e abrigam alguns de seus filhos solteiros ou separados e os netos daí decorrentes.

Por vezes, começo meu dia sentando nos bancos fixos e rentes à parede do corredor principal do Centro. Ali já encontro senhoras e senhores dispostos a começar um papo. Outras vezes, sigo diretamente ao "grupo de apoio" ou ao "grupo da ginástica". 6 Embora eu sempre parta para a casa das pessoas, para visitas posteriores e mais alongadas, há um risco de começar os contatos dentro do Centro. Reconheço que posso incorrer em conhecer apenas $O$ "sick role" parsoniano, sobre o qual acabei de tecer um quadro de críticas já bastante consensual. Como dito acima, ser apenas "paciente", significa tender a aceitar e pautar-se pelo modelo explicativo biomédico (Kleinman 1980), por uma relação geralmente hierárquica, paternalista e desigual com uma equipe de ditos "especialistas", e por um discurso ideal e dourado de como realizar o tratamento. Aqui, portanto, cabem algumas ressalvas. Primeiro, as pessoas resistem em sucumbir à condição onipresente de "paciente". Os dados que escolhi apresentar aqui mostram justamente como, também no espaço hospitalar, essas pessoas estão, a todo tempo, inventando formas de reaver sua autonomia e tomar decisões que consideram mais apropriadas para o cuidado da sua doença crônica. Assim, o "sick role" pode até ser uma expectativa anunciada pela equipe clínica e até esperado pelas pessoas em certas circunstâncias, mas não necessariamente é aceito a todo o momento e de forma acrítica por estes frequentadores.

Segundo, tenho tentado não ser confundida com a equipe, rol de personagens face ao qual mais facilmente se permanece no papel de paciente. Não uso roupa branca, tampouco jaleco ou crachá. Sento-me nos espaços destinados aos usuários, onde nunca se vê funcionários do Centro fazendo o mesmo. Tento comunicarme de forma clara, sem muitos floreios ou rodeios, priorizando palavras e expressões semelhantes às que eu percebo serem utilizadas por esse público, evitando também termos ou jargões técnicos da biomedicina, das cartilhas e dos programas de televisão ou mesmo da antropologia e da universidade. Tomo notas rápidas em um caderno de campo pequeno, toda vez que surge algo interessante, numa clara demonstração de valorização do que me é dito. Embora o caderno ostente meu pertencimento ao mundo do letramento e da escolaridade - aspecto que pode me distanciar destas pessoas, muitas das quais, analfabetas - julgo importante demarcar que a conversa, tantas vezes informal, bem humorada e até íntima, é também uma relação de trabalho e pesquisa. Quero, assim, lembrar meus interlocutores de que estão 
falando em um dado contexto, com uma dada agenda, estimulando que escolham o que me contar. Também por essa razão, prefiro a materialidade e presença do caderno do que a quase invisibilidade e, por vezes, indiscrição do gravador de áudio.

Terceiro, pelo fato de naquele cenário "falar de doença" ser algo bastante naturalizado e que, nos locais onde escolho me posicionar, a troca de informações sobre a convivência com essas doenças ser uma prática altamente valorizada (como se verá nas seções seguintes), considero que tenho acesso a dados "relativamente líquidos", digamos, na forma de uma enxurrada densa de comentários, opiniões e análises de como é viver com hipertensão ou diabetes. É preciso, como tenho dito, relativizar isso no sentido de que, fora dali, talvez essa monotemia sobre a cronicidade não seja igualmente intensa. E, por fim, tento balizar isso com perguntas sobre o que se passa fora daquele espaço, suscitando histórias de vida, da família, da vizinhança e do bairro como estofo contextual que ajude a entender as medidas terapêuticas encontradas.

\section{COMO O “CONTROLE” É PERCEBIDO E PRATICADO PELOS ADOECIDOS}

A seguir, apresento três conjuntos de dados etnográficos que revelam as principais estratégias de "controle" empreendidas pelas pessoas que tenho conhecido no bairro. Primeiro, veremos de que maneira medir com frequência os índices corporais, ter aparelhos de medição a mão e contar com uma rede de intérpretes sobre os números revelados pelos aparelhos ajudam a entender o que denomino de uma "gramática dos números". Segundo, uma nova relação com os medicamentos é estabelecida, resultando em uma tática posológica própria para a convivência com a hipertensão e a diabetes. Terceiro, as emoções surgem como elemento determinante na alteração das taxas de pressão e glicemia sanguíneas. Números, medicamentos e emoções - essa tríade nos ajudará a compreender como o "controle" dessas doenças é realizado pelos guarirobenses da pesquisa.

\section{O "CONTROLE" A PARTIR DE UMA GRAMÁTICA DOS NÚMEROS}

\section{MEDIR SEMPRE, COMPARAR RESULTADOS E CONHECER A PRÓPRIA "NORMALIDADE"}

D. Rita é uma senhora de 1942. Nasceu em Coremas, PB, e veio para o Distrito Federal em 1974. Em 1979, com seus seis filhos, mudou-se para uma "casa da SHIS” na Guariroba. Em 2011, já convivia com a hipertensão há seis anos. Frequenta o "postinho", mas faz os exames em laboratórios privados, talvez porque o filho que é bombeiro ou aquele que é bancário tenha lhe incluído em seu plano de saúde. Ela mede sua pressão com alguma frequência, "na farmácia ou no posto", explica. Perguntei quando ela acha que precisa medir e ela foi certeira, "Ah, quando eu sinto dor de cabeça". D. Rita recorre aos aparelhos quando sente algum sin- 
toma que destoa de sua sensação de bem estar. Mas esse cenário é o menos frequente, pelo que tenho observado. Mais comumente as pessoas medem sua pressão sempre que há alguma oportunidade para tanto, como nas consultas de rotina ou ao acompanhar alguém até o "postinho", ao passar na frente de uma farmácia comercial ou numa feira que ofereça esse serviço.

A uma das dezenas de senhoras que observei ter a pressão sanguínea aferida na sala de acolhimento, perguntei se o índice era verificado diariamente. Ela respondeu, "Não, é porque vim tomar vacina". A prática dessa senhora é mais recorrente por ali do que a de D. Rita, que só verifica se sente algo diferente. Medir-se quando não há sintomas permite que se conheça seu padrão de "normalidade". É possível comparar esse padrão com os números que surgirem quando houver algum mal estar. Nessas ocasiões, será possível saber se a pressão ou a glicose está alta, muito alta, alta demais, por exemplo. Por outro lado, diante de um número "bom" ou "normal", o mal estar será relacionado a outros fatores, não necessariamente ao "problema da pressão" ou ao "problema de glicose". Medir sempre, ao longo da vida, é uma prática amplamente instituída como uma ação de autoconhecimento. Ouvi muitas vezes que "alto para mim é ..." ou "esse é baixo para mim" etc. Os números ganhavam vida, passavam a ter um peso nada desprezível para orientar como se estava naquele dia específico e também que tipo de "hipertenso" ou "diabético" se é, em geral. Medir sempre é uma forma de desenvolver uma "expertise de si", como sugerem Taylor e Bury (2007), aos nos falarem dos "expert patients" que, ao longo da convivência com uma doença crônica, se tornam uma espécie de especialistas do seu próprio caso. Além disso, medir sempre permite que se conheça o sistema numérico e classificatório de cada doença, seja a hipertensão arterial, seja a diabetes mellitus. Isso não é pouco, nem é aprendido rapidamente. Uma coisa é conhecer como as autoridades sanitárias oficiais percebem esses números e, mais importante, como os moralizam; outra coisa, igualmente importante, é o adoecido ser capaz de se inserir nesse quadro numérico e balizar todos os acontecimentos que lhe sucedem em relação aos números que aparecem nos visores dos aparelhos de medição.

O que desejo registrar aqui é a importância dada por essas pessoas à prática de "medir", "ver" ou "tirar" a pressão ou glicose. Lembro de S. Manoel, um senhor que conheci pelo corredor do Centro. Ele tinha ido trocar um glicosímetro antigo por um novo, compatível com as fitas que o Centro estava a distribuir naquele momento. Ele me disse, "Não meço muito. Mas andei fazendo umas estripulias, então, acho melhor voltar a medir, voltar a controlar o açúcar", explicou. "Controlar o açúcar" pode ser comer menos doces e sobremesas, mas também pode ser verificar a glicemia mais seguidamente. Ao que parece, para ele, "fazer estripulias" estaria numa ponta contrária ao "medir" seus índices cor- 
porais. Diferente da senhora que abriu essa seção, D. Rita, em geral, as pessoas tendem a conferir seus índices com frequência, passando mal ou não, e essa já constitui um prática relevante de cuidado da saúde e, na acepção corrente por ali, de "controle" da pressão ou da glicose.

"Tirar a pressão" talvez, de fato, tire a pressão. Verificar como está a pressão sanguínea a cada momento significativo do dia (ou da semana) é um ritual que ajuda a traduzir o que está acontecendo, de fato, nesses momentos. Poderia ser dito que, diante dos sucessivos resultados que aparecem nos esfigmomanômetros, aos poucos a "hipertensão" se alivia e vira apenas "tensão". A Ao ver como está a pressão, essas pessoas parecem estar me dizendo que o corpo e seu mais importante fluido - o sangue - são bons idiomas para entender o dia a dia e suas atribulações nem sempre evitáveis. Aqui, estou diante de uma poderosa metáfora, como Gay Becker (1997) tão bem me ensinou a observar, sendo usada para se referir à uma prática de cuidado corporal que reflete diretamente as emoções e o bem estar e, ao mesmo tempo, sobre os mesmos.

\section{TER OS EQUIPAMENTOS À MÃO}

Desde o início dessa pesquisa, tenho observado uma pronunciada popularização dos equipamentos mensuradores nas casas das pessoas ali na Guariroba. Aventamos que esse fenômeno não se circunscreve apenas ao bairro, mas se generaliza por todo país. Esse é um fenômeno relativamente recente $\mathrm{da}$ última década e já motivou uma pesquisa específica por nossa equipe (Bezerra 2011; Bezerra \& Fleischer s/d). Aqui, o que vale registrar é que, além de valorizar a medição constante dos índices corporais, ter acesso cotidiano aos equipamentos é uma segunda prática importante para instaurar uma forma de cuidar das doenças crônicas. Não se deseja receber notícias destes números apenas pelas mãos de profissionais da saúde, mas, sim, medir por conta própria e a qualquer momento.

A esposa de S. Manoel, que conhecemos há pouco, se chama D. Sebastiana. Enquanto o marido tem um glicosímetro, ela tem um esfigmamômetro e explicou que "mede de todo mundo pela vizinhança”. E continuou a me contar, "ele é bem velhinho, comprei ainda em 2002, mas todo mundo na rua me pede para medir a pressão deles". D. Ana Roberta, baiana de Barreiras, BA, está na Guariroba com seu marido pedreiro e dois filhos desde 1977. Ela contou que "antes [da separação traumática da filha], eu era normal da pressão. Era, assim, 13 por 7. Eu media sempre quando vinha fazer consulta ou exame de rotina". À época em que a conheci, D. Ana Roberta estava passando pelo que Bury (1982) chamou de "ruptura biográfica”, já que o diagnóstico da hipertensão tinha lhe sido comunicado há pouco tempo e ela ainda se debatia para fazer sentido do mesmo em sua vida cotidiana. Ainda assim, D. Ana já sabia facilmente onde poderia contar com uma aferição, caso se deparasse com algum sobressalto em seu bem sentir: 
"Tem uma vizinha nossa lá. Ela é mulher do bombeiro. Ela tem problema de pressão e tem o aparelho. Ela não cobra pelo serviço. Não, não. Ela faz por caridade com as pessoas mesmo. Ela fez foi um curso de primeiros socorros, essas coisas. E por isso, ela sabe medir. Ela acode os vizinhos por lá. Mas, sabe, eu estou até pensando em comprar um para mim. Para eu poder medir em casa mesmo."

Muitas vezes ouvi narrativas semelhantes às de D. Sebastiana e de D. Ana Roberta. Uma era a vizinha que oferecia os serviços; a outra, a vizinha que contava com os serviços de um aparelho à disposição. Embora, ao passar a tarde pelo corredor de espera do Centro eu visse dezenas de pessoas para lá se dirigirem simplesmente para aferir a pressão, o Centro não é, de longe, o local que monopoliza o uso destes aparelhos. Não é preciso nem deixar a própria rua, na casa ao lado já é possível contar com um aparelho e alguém versado em utilizar e interpretá-lo. Ou então, como D. Ana terminou dizendo, em breve até da vizinha ela se tornará independente, ao adquirir seu próprio esfigmamômetro.

Certa tarde, quando apresentava nossa nova pesquisa à Dra. Amanda, a atual diretora do Centro, expliquei que, além de conversar com as pessoas pelos corredores do lugar, estendia minha presença às casas, onde conversas mais parcimoniosas poderiam acontecer. Um dos objetivos era conhecer se, quando e como as pessoas utilizavam os equipamentos. A diretora, que também atua como ginecologista no local, reagiu prontamente,
"Isso é um horror. Eles não sabem medir direito. Para medir, tem que estar em repouso, não pode ter ficado sentado, não pode cruzar as pernas e tal. Se não, os números saem todos errados e eles acabam mudando a medicação por conta disso. Já que vocês estarão indo nas casas, podem ver se os equipamentos estão aferidos? Vocês medem com o [equipamento] manual e comparam com o [equipamento] digital. Isso é super importante."

Meu espanto maior não foi com o fato de ela confundir nossas atribuições de cientistas sociais com as de cientistas médicos, mas de rapidamente perceber o potencial patrulhador e também controlador de nossa presença nas casas, talvez semelhante ao que imaginasse para os agentes comunitários de saúde, por exemplo.

Interessante também nesse comentário da diretora é o entendimento, que só reforça os dados que apresentei até aqui, de que as pessoas são muito ativas no cuidado da própria saúde e, dentre os vários elementos que orquestram para interpretar os sinais de mal estar, estão os números verificados frequentemente nas máquinas de medir. O que me inquieta, contudo, é o paradoxo que parece pairar no desabafo da médica. Se por um lado, o "controle" é enunciado como tarefa compulsória esperada por parte dos "crônicos", por outro lado, a médica parece desejar confinar esse "controle" aos padrões e paredes do Centro em vez de reconhecer que essas pessoas estão colocando na prática diária o que é preconizado pela instituição. Afinal, qual seria a diferença entre 
medir a pressão com as enfermeiras do Centro e medir em casa, já que, nas duas situações, números e, consequentemente, comportamentos são gerados? Parece-me que a autonomia da automedição e, sobretudo, do autocuidado é o que mais incomoda essas autoridades médicas.

\section{CONSIDERAR VÁRIAS FONTES DE INFORMAÇÃO}

Assim, diferente do que Dra. Amanda gostaria, percebo que esses guarirobenses com quem tenho conversado valorizam poder contar com várias fontes de informações sobre suas doenças crônicas. Dentro do Centro, os repetidos momentos de espera por consultas, por aferições, resultados de exames e entrega de medicamentos são também momentos de conversa, troca de experiências, e práticas de aconselhamento. Nos "grupos de apoio”, pessoas que se conheceram ali há mais de cinco ou seis anos, voltam sempre a se encontrar e podem atualizar sobre a doença que enfrentam diariamente. Fora dali, nos pontos de ônibus, nos mercados e nos portões das casas também há tempo para reportar os sintomas do dia ou da semana e checar por soluções ou alívios. Dentro de casa, há ainda mais intimidade para avaliar as terapêuticas prescritas face às sensações percebidas. Parece que, quanto mais distante do Centro, mais diversas são as possibilidades de debate sobre os "problemas de pressão e de glicose", numa relação inversamente proporcional ao "controle" unilateral e pretensamente monopolizado pelas autoridades clínicas.
Ao considerar os números, tão presentes nessas condições crônicas, a discrepância é sempre mote para reflexão. Claro que essa reflexão volta rapidamente num intricado autoexame, que escrutina os últimos comportamentos em termos de "estripulias", como disse S. Manoel acima. Mas também abre um flanco de questionamento sobre os aparelhos, as pessoas que os manejam, os medicamentos, e, por fim, as prescrições emitidas pelo Centro e outros espaços terapêuticos.

À primeira vista, o ritual da medição seria um momento bastante oportuno para se comentar sobre os números e aventar interpretações. Mas o que tenho observado é que isso acontece muito mais em casa e na rua, do que no Centro, diante da equipe. $\mathrm{Na}$ "sala de acolhimento" e no "grupo de apoio", os números são anunciados em vOZ alta pelas técnicas em enfermagem. As pessoas, quando muito, perguntam "Está bom?" ou "Está alta?". Esses monossílabos são respondidos com outros, "Sim”, “Tá”, “Tudo bem”, ou no máximo algo como "Um pouco alta" ou "A mínima está alta". Raríssimas são as vezes em que o diálogo continua, e quase nunca por parte das atendentes. Nessas ocasiões, é a pessoa que se espanta, para o bem ou para o mal. Uma senhora disse, diante de um "14 por 8", "Tirou minha dúvida, tava com umas tonturas, mas tá normal". Já um senhor exclamou bravo, ao ouvir que estava "18 por 8", "Mas hoje cedo tava 16, agora tá 18 ! Como assim?”.

As técnicas em enfermagem, principais responsáveis por atender estes pacien- 
tes, me explicaram que o diálogo após uma aferição é minguado porque, se os números estão alterados, o paciente já sabe que "aprontou". Se o mesmo faz algum comentário, elas deduzem que seja um neófito na doença, recém diagnosticado como "hipertenso" ou "diabético" e que ainda tateia pela gramática dos números. Assim, embora todos aqueles com números "altos" sejam rapidamente considerados "relapsos" ou "relaxados", a equipe percebe que os primeiros, os mais experientes, já internalizaram o "controle" melhor do que os segundos, os calouros. A equipe parece ter um pouco mais de paciência com o segundo grupo, que está em franca socialização no novo status de "crônico", mas vão exigir que todo mundo "ande na linha". Por outro lado, em meu lento entendimento dessa suposta anuência silenciosa diante das aferições, penso que os usuários deixavam esse diálogo para o consultório, onde, diante do médico, poderia haver um momento individual e mais privativo, em vez $\mathrm{da}$ exposição coletiva que acontecia na sala de acolhimento ou na sala de reuniões, durante o "grupo de apoio". Por fim, não argumentar frente a um "número alto", em vez de equivaler a resignação ou passividade, pode ser o contrário, uma percepção de seu valor relativo, isto é, talvez passaram a considerar esse espaço de enunciação mais uma e não a única fonte de informação.

Em geral, as pessoas simplesmente ouvem os resultados e já saem para chamar o próximo da fila. É de volta à fila que eu ouço e acompanho os animados desdobramentos sobre os números como "14 por 8" ou "18 por 8". D. Lucia veio em 1974 de Campina Grande, PB, é ex-trabalhadora doméstica, casada com um funcionário da divisão de "Parques e Jardins" do Governo do Distrito Federal e com quem teve 13 filhos, "mas criou só 10 ". Eu a conheci ao conversar com D. Rita, que apresentei acima, já que as duas estão no mesmo "grupo de apoio", além de serem vizinhas e conterrâneas. D. Lucia me contou que

"Da última vez, o médico me disse que eu tenho diabetes. Disse que o exame deu 128 e que isso é diabetes. Mas eu vou continuar tomando remédio toda a vida? Eu vou fazer essa pergunta para ele hoje. Depois, mediu aqui e deu 82 . Na minha vizinha, [o meu número] deu 121, e isso foi na mesma semana. Como é que pode? Eu vou perguntar para ele. O meu mastologista me disse que eu preciso ir num cardiologista para ver se eu tenho que tomar medicamento mesmo."

O assunto continua no caminho de volta e já dentro de casa. Elementos relevantes para o debate são relembrados, esposas zelosas pela saúde dos maridos aproveitam para criticar comportamentos que consideram reprováveis, uma briga com um parente passa a figurar como um evento explicativo para o tal "número alto" etc.

Por mais que este espaço biomédico seja valorizado, pelo fato de contar com especialistas e tecnologia, o desencontro de números exige que explicações sejam buscadas, em geral fora dali. Aparelhos "de bombinha" são mais confiáveis do 
que os modernosos aparelhos "digitais"; vir de bicicleta ou caminhando rápido pode fazer o sangue "agitado"; a enfermeira é novata e não sabe fazer a operação; e, como veremos na seção seguinte, alguma "preocupação" pode afetar e incrementar a pressão - estas são apenas algumas de tantas possibilidades explicativas para um indesejável “18 por 8", por exemplo. Embora a equipe profissional do Centro também considere explicações semelhantes para os pacientes "relaxados" ou "descontrolados”, as pessoas só vão listar essas possibilidades entre audiências mais amenas e informais, geralmente seus pares de espera. Para minha surpresa, já que eu esperava que os momentos de aferição pudessem servir de oportunidade de diálogos clínicos envolvendo todos estes atores, os números só são geradores de boas conversas e ponderações quando outros usuários do Centro, familiares em casa ou antropólogos em campo se transformam em escutadores atentos e cúmplices. Ter o aparelho à disposição, em casa ou na vizinhança, tornava-se, portanto, providencial na criação de uma constelação numérica de onde derivar interpretações sucessivas, cumulativas e relevantes sobre a própria saúde.

Vale ainda mencionar que o Centro não figura apenas como um espaço de controle. É ali que muito da socialização do doente crônico acontece, no momento austero das aferições públicas, mas também nas relações mais horizontalizadas com o atendente da farmácia que é um ex-vizinho ou com outro usuário que também mora por ali e provavelmente é parente de algum conhecido. Essas conversas, aparentemente despretensiosas, integram a contínua socialização do sujeito no quadro da cronicidade. Aprender a reconhecer sintomas e relacioná-los com as doenças, alargar o leque explicativo, associar os inúmeros elementos desse leque de modo a fazer sentido de cada quadro sintomático são conhecimentos finos que, como estou tentando mostrar, são gradual e coletivamente adquiridos.

\section{UMA NOVA POSOLOGIA DOS MEDICAMENTOS}

Lembro-me de uma ocasião em que o farmacêutico do Centro me explicou que muitos pacientes ficam chateados de esperar várias horas por uma consulta e, ao final, ser-lhes prescrito apenas um medicamento, por exemplo. Passei bastante tempo etnografando o funcionamento da Farmácia do local e o que Fernando estava me explicando era sobre uma das maiores expectativas dirigidas aos centros de saúde: o acesso, via consultório e receita médica, aos medicamentos gratuitos. Esse era um dos motivos que levava as pessoas a enfrentarem filas, esperas e diferentes formas de controle institucional.

Ainda assim, no caso dos adoecidos crônicos, eu observava táticas interessantes que destoavam ligeiramente desse apreço incondicional pelos medicamentos. Os pacientes crônicos são uma das prioridades da atenção básica e, portanto, foi desenhado um acesso facilitado dos mesmos às consultas e remédios. Passam pelos médicos duas ou 
três vezes ao ano com consultas automaticamente marcadas, retiraram mensalmente seus fármacos na farmácia local, mediante o uso de um cartão, onde o farmacêutico (que anota a data e a quantidade dos itens) realiza o "controle" entre a dose prescrita e retirada.

Embora contassem com esse acesso aparentemente facilitado, as pessoas que conheci não sucumbiam automaticamente à prescrição. Desconfiavam dos fármacos: reconheciam efeitos colaterais (e as pílulas eram tidas como "fortes demais") ou os aparelhos revelavam a pressão que teimava em ficar alta (e as pílulas figuravam como "fracas demais"). Os medicamentos tinham sua confiabilidade e eficácia testadas em casa e discutidas nos espaços coletivos onde as doenças eram mote de animadas conversas. Podia-se, por fim, aderir, aderir parcialmente ou rejeitar o medicamento.

Fui entender esse quadro tanto por frequentar algumas dessas casas quanto pelas explicações dadas pelos atendentes da farmácia, atentos às práticas dos usuários. Numa manhã, uma senhora chegou para pegar os medicamentos para si e para o marido. Fernando colocou todas as cartelas - eram dezenas delas - em cima do balcão. Em seguida, ela começou a sorti-las em voz alta: "Esse aqui eu vou levar menos porque tem lá ainda. Esse aqui não vou levar, tem muito lá em casa. Ah, esse estou precisando. Esse não vou levar porque passo mal com ele". Agradeceu, meteu na sacola de supermercado o que lhe apetecera e despediu-se. O farmacêutico virou-se para mim e, num misto de tradução e desabafo, explicou, "Você vê aí como eles fazem: Ela não quer levar tudo que está na receita porque tem em casa. Na verdade, está sobrando medicamento da vez passada porque ela não está usando na quantidade certa. Ela está mudando a dosagem, o consumo. E a mesma coisa para o marido dela".

Em geral, os pacientes nem explicam em voz alta seu comportamento como essa senhora fez. Simplesmente aparecem com menos ou mais regularidade à farmácia, conforme o consumo dos itens. Pelo "controle do cartão", os farmacêuticos podem notar há quanto tempo aquele paciente crônico não aparece por ali, como me disse Jonatas, o farmacêutico encarregado:

"Eu vejo eles pegarem menos do que o médico mandou. Tento entender por que: eles estão tomando uma dose menor. É só melhorar um pouco que ele toma um por dia, em vez de dois por dia. Ou pula um dia e aí a quantidade que ele pega na farmácia dura por dois meses. E se chega na farmácia querendo mais do que o médico mandou, pode saber que estão tomando em dobro, estão sentindo mal e não contaram isso pro doutor na consulta.

Uma nova posologia era posta em ação, baseada, sobretudo na experimentação realizada entre os fármacos e as reações corporais observadas. Parecia que cada pessoa buscava, em primeiro lugar, conhecer sua "normalidade" e os fatores que alteravam essa normalidade, geralmente "preocupações" específicas, e, em segundo lugar, como cada item receitado dialogava com esses estados, mais ou 
menos normais. Um conhecimento personalizado era construído lentamente, proporcionado, sobretudo, pela convivência prolongada e compulsória com a doença crônica em questão."

Jonatas uma vez sintetizou como percebia seu trabalho, diante de minha pergunta sobre os pacientes que vinham trimestralmente à farmácia quando o ideal era a visita mensal, "Ah, a gente não só entrega remédio aquil. Quer dizer, a equipe da farmácia do Centro se empenhava em observar a adesão das pessoas em relação à terapêutica receitada e se atribuía o papel de esclarecer sobre os supostos riscos de pular ou dobrar a medicação e, em casos extremos, retinha o cartão e encaminhava a pessoa à uma nova consulta. Reforçava, assim, a "frente do controle" e se imbuía de aprumar os comportamentos dos usuários. Contudo, ao parecerem definir como melhor "controlar" a saúde, as pessoas instauravam seus próprios regimes posológicos e deixavam de comparecer à farmácia com a regularidade prescrita e, na ocasião em que precisassem suprir suas dispensas, apareciam ou mandavam outras pessoas em seu lugar para buscar os medicamentos. Evitar que o próprio "dono do cartão", como chamavam, fosse ao estoque era evitar também que admoestações lhe fossem dirigidas. Como no exemplo acima, a esposa buscava o remédio do marido. Vi também netos adolescentes se apresentarem em nome dos avós e filhos adultos ajudarem os pais nessa tarefa. Fernando e Jonatas mandavam recados com suas broncas e avisos de cautela, mas isso chegava às casas com efeito atenuado e indireto.

\section{CRONICIDADE E EMOÇÕES}

Deixe-me retomar a história de D. Ana Roberta, iniciada acima. Ela continuou explicando o momento em que sua pressão se "descontrolou":

"Antes, eu era normal da pressão. Era, assim, 13 por 7 . Mas a minha filha separou faz pouco. Ela tinha nove anos de casada. Eu já não durmo, já não como mais direito. Você sabe o que é ouvir do seu marido, "Eu não tenho mais amor por você"? Menina, não é brincadeira, sabe. É triste demais uma coisa dessas. Afe Maria. Ela ouviu isso dele. Tinha tudo dentro de casa, sabe. Casa montada, bonita. Ele até falou para ela ficar com a casa. Mas ela não trabalhava, como ia pagar a prestação? Ia acabar com dívida, Deus me livre. Voltou para casa. Ela diz assim, "Mãe, não quero nada do passado". Deixou uma casa linda, linda, só vendo. Cada panela de inóx que ela deixou para trás! Nossa. Uma tristeza. Mas ela tá procurando emprego. E é bonita, nova, logo arruma outro namorado."

Quando eu perguntava sobre os motivos para uma pressão subir, eu ouvia sobre medicamentos que "fazem mal" ou que simplesmente "não fazem efeito nenhum”. Também comentavam dos comportamentos que lhes "tiravam da linha", geralmente associados à comida, tabaco, álcool e lazer. Mas era de outra natureza de fenômenos que mais me contavam, como D. Ana Roberta acabou de lembrar, quando algo tão perturbador lhe rouba a fome e o sono. Outras pessoas explicaram da mesma forma que D. Ana: 
"A pressão é coisa de agonia, de aperreio. É o emocional da gente que fica alterado e afeta o sangue, a pressão do sangue. Meu pai morreu com 95 anos, ele morreu de câncer. $\mathrm{Eu}$ fui cuidar dele e tudo. Mas foi muito difícil para mim. Foi nessa época que minha pressão começou a subir. Foi coisa do emocional mesmo. (D. Antonieta)

Ah, eu acho que é coisa do momento. Você tá bem, mas se fica nervoso, aí já sobe a pressão. Aí, você toma o medicamento, em uma hora, ele já faz efeito e você fica com a pressão boa de novo. Mas se você se agita com alguma coisa, volta a subir. (S. Raimundo)

Eu acho que o que aumenta a minha diabete é uma raiva que a gente passa. Aí, o sangue agita e agita a pressão ou a glicose, no meu caso. Por exemplo, eu tenho três netos em casa. Minha filha mora com a gente e eu ajudo a criar os meninos. Ela sai pro trabalho e eu que levo os três para escola. Aí, é aquela coisa, acorda, começa a enrolar, aí já atrasa para a escola. Eles me fazem passar essa raiva todo dia de manhã. Eu dou bronca, apresso, para ver se a gente sai logo. Mas é difícil. Quando eu era mais novo, eu não ligava muito pras coisas. Passava menos raiva, eu acho. Hoje, você tem neto, tem filho. Eu tenho um filho que me dá muito trabalho. Tudo isso vai te transtornado, te deixando estressado. É assim." (S. Osmar)

Várias pessoas me contavam como esses "eventos críticos", como diria Giddens (1991), como a morte ou o divórcio nos exemplos acima, não só mudam o rumo corporal definitivamente, mas continuam alterando-o, ao longo da doença instalada. Aqui, essas pessoas parecem aceitar as explicações biomédicas sobre estilo de vida, alimentação e genética, mas, por outro lado, priorizam os eventos emocionalmente intensos como geradores de transformações sistemáticas e irreversíveis. A vida e o corpo, a biografia e o sangue são inter-relacionados. $\mathrm{E}$ as emoções vão sendo medidas, contadas, quantificadas. Assim, a separação de sua filha "começou o problema", mas estes são intensificados com pequenas ocasiões conflitivas do cotidiano, como lembrou D. Ana Roberta: "Uma das coisas que mais me perturba a saúde são as crianças lá da minha rua. Eles jogam bola bem na frente da minha casa. Nem para jogar na frente de outra casa. Mas não, é ali em casa. E a bola fica batendo na grade lá de casa o tempo todo. Aquilo me deixa muito perturbada."

Anotei uma gama de emoções que foram atreladas às alterações sanguíneas. Como visto, "raiva", "agonia", "nervosia", "ansiedade", "aperreio" são mencionados com frequência ao localizarem os "picos" ou "crises" da pressão alta ou glicose. Mas é "preocupação" a categoria que mais se apresenta. Esse raciocínio foi-me comunicado pelo motorista de ônibus "encostado", S. Osmar, citado acima. Um capixaba nascido em 1964 e desde os seis anos de idade no Distrito Federal, ele disse: "Eu acho que é assim, a preocupação que você tem com alguma coisa dá um nervosismo em você". E outro depoimento bastante revelador, nesse 
período de trabalho de campo, chegoume de uma senhora de pele amarronzada clara, portando óculos "com fundo de garrafa" que ampliavam seus pequenos e ligeiros olhos escuros. Parecia um pouco inquieta, mudava de posição no banco constantemente. Os longos cabelos eram presos numa espécie de coque ou trança no alto da cabeça. Explicou que "Meio dia, sou baiana. Meio dia, sou goiana", e riu depois. Nasceu em São Domingos, na Bahia, município na fronteira com o estado de Goiás e convive com a hipertensão desde 1974, quando tinha 28 anos de idade. Perguntei à D. Leonice se, por conta da hipertensão, ela tomava algum medicamento:

"Sim, tomo vários. Mas o importante mesmo é o controlado, o de dormir. O ametril e o diazepam são, os dois, remédios para dormir, para relaxamento, para o sistema nervoso. Essa noite, por exemplo, eu não dormi quase nada. Acho que acordei umas 3h da manhã e estou até agora acordada. Não consigo dormir de noite, não consigo dormir de dia. É uma tormenta isso. Por isso, quero pedir para que o médico volte com o ametril. É isso que eu mais quero, sabe. Esses medicamentos são para o relaxamento, para conseguir dormir. São importantes para mim. Fico muito melhor com eles."

D. Leonice está a explicar que é preciso usar um medicamento para controlar o nervoso. Com isso, o nervoso não vai afetar a pressão arterial. Controlar o nervoso é, por tabela, controlar a hipertensão. Embora essas pessoas reconheçam com facilidade que a comida e os medicamentos certos ajudam a "controlar" os índices corporais, como os profissionais de saúde têm insistido em dizer, esses não bastam. Talvez seja mais fácil fazer uma espécie de "autocontrole" e, na hora e na quantidade certas, fechar a boca para a comida salgada, gordurosa ou doce demais e abrir a boca para as pílulas (contra a hipertensão, a diabetes ou mesmo o nervoso). Mas "controlar o nervoso" é tarefa muito mais desafiante porque, em primeiro lugar, pelo que entendo, não é um fenômeno produzido por uma má conduta individual, mas por forças externas, geralmente coletivas. São elas que geram a preocupação. E, na separação de uma filha, na morte de um pai, no cuidado diário dos netos, não há como simplesmente recusar a situação - como se faria com um pedaço de torresmo ou de rapadura. Não há como se esquivar das relações sociais. Em segundo lugar, D. Leonice está a me dizer que precisa de ajuda para "controlar" o inesperado e o incomensurável que é o afetar-se com o sofrimento próprio ou alheio. Ela está explicando que não é na comida e nem nos antihipotensores que está o controle, mas no controle do nervoso, já que as "preocupações" infelizmente não cessam de surgir, sobretudo, como lembra S. Osmar, no momento da vida em que as responsabilidades se avolumam quando alguém se torna pai, avô, provedor. $^{8}$

\section{CONSIDERAÇÕES FINAIS}

Até aqui, tentei descrever em maior detalhe como outra lógica de controle - que envolve o monitoramento dos ín- 
dices corporais, dos aparelhos, dos medicamentos e das "preocupações" - é realizada pelas pessoas que convivem com doenças crônicas e frequentam, também por isso, este Centro de Saúde do bairro da Guariroba. Por tabela, uma das consequências dessas ações é a instauração de outro regime de controle, autodeterminado, em vez de simplesmente receber e seguir o que é sugerido pelas autoridades sanitárias locais.

Se, no caso das doenças agudas, as ideias de "tratamento" e "cura" ficam claramente definidas, no caso das doenças crônicas, parece que "controlar" passa a ser preconizado como a única alternativa de manejo diário (Guell 2011). Parece que, a partir do que há à disposição em termos terapêuticos até o momento, a única possibilidade oferecida às pessoas que convivem com doenças como a hipertensão arterial sistêmica e a diabetes mellitus é conscientizar-se das mesmas e exercer um minucioso e contínuo monitoramento de todas as variáveis conhecidas ou, no mínimo, supostamente relacionadas a estas patologias. O que essa pesquisa tem me ensinado é que "controle" pode receber muitas acepções e, em meus meandros pela Guariroba, e venho afinando a minha escuta para as formas com que essas pessoas optam por "cuidar" da - mais do que "controlar" a - própria saúde. Aqui, procurei descrever algumas das práticas de atenção mais recorrentes para estas duas doenças, especialmente em relação aos índices corporais, os medicamentos, as emoções e os trânsitos pelos serviços primários de saúde.
Noto que as pessoas e seus cuidadores oficiais estão, por vezes, navegando por pressupostos diferentes. Por enquanto, localizo três possibilidades nesse sentido que comento à guisa de conclusão, embora aqui figurem provisoriamente, inspirados pelos dados etnográficos acima apresentados.

Primeiro, em relação ao pressuposto da temporalidade, as pessoas parecem considerar o tempo presente e negociado, com suas "coisas do momento" e "preocupações" que acontecem de forma inesperada, para entender porque uma "pressão sobe". Elas estão "ouvindo o presente", a cada dia. Ao passo que a equipe do Centro tende a se referir a um tempo passado ou futuro: por um lado, determinado pela ideia fisicalista da hereditariedade das doenças crônicas; e, por outro, ao adotar incondicionalmente uma profunda mudança de comportamento em termos de dieta, exercícios físicos e medicamentos.

Segundo, as pessoas que eu conheci ali nos bancos de espera me contaram de como o "outro" é quem lhes alterava os índices e, em consequência, o estado de saúde. Era o ex-genro que deixou a filha de D. Ana Roberta, eram os netos desobedientes de S. Osmar, por exemplo, que faziam essas pessoas "passarem raiva" e sofrerem com estes efeitos sobre sua doença. Já os profissionais mencionavam os "hipertensos relapsos" ou "relaxados" que, por não "fecharem a boca", não conseguiam "andar na linha" e ficarem "controlados". Enquanto o primeiro grupo navegava por uma causalidade externa aos limites do corpo e do indivíduo; o 
segundo percorria uma causalidade interna, tendendo até a uma culpabilização exclusivamente individual em termos de comportamento ou genética.

Terceiro, por fim, senhoras e senhores como S. Osmar, D. Ana Roberta, D. Leonice, D. Lucia, D. Rita, D. Cristina e S. Manoel estão insistindo que, embora frequentem o Centro e sigam, mais ou menos, as prescrições de comportamento e medicamentos, o que é realmente necessário é se atentarem às relações sociais em que estão envolvidos. Não adianta "controlarem" a hora de engolir o Captopril ou reduzirem o sal do almoço, se há conflitos, contendas, desconfortos à sua volta. Tudo isso lhes afetará os "nervos" e as emoções ficarão em pandarecos, refletindo inevitavelmente sobre a "pressão" e o "açúcar" do sangue, desbancando qualquer efeito das pílulas, mesmo as tidas como "fortes". O que importa é conseguir instaurar uma atmosfera harmônica em casa e nas relações relevantes fora dali. Enquanto pode parecer que eles estejam me atentando para uma expectativa quase utópica, de um mundo ideal sem atritos e conflitos, prefiro entender que estejam também se referindo à complexidade implicada no cuidado da hipertensão e da diabetes. Muita coisa pode afetar o "sangue", isso é o que parecem insinuar em seus depoimentos. Já nos espaços hospitalares, estas pessoas ouvem que outras porções precisam ser controladas: os alimentos, os números, o colesterol nas veias. Aqui, o "controle" é parcial, fracionado, fragmentado ao não considerar como há uma inter-relação entre todas as partes - comida, gente, família, trabalho, vizinhança, história do bairro, remédios etc.

Talvez pelo fato destes pressupostos dos usuários e das equipes serem um pouco desencontrados, o cumprimento das prescrições biomédicas resultem como um desafio. Não quero, contudo, reforçar um quadro polarizado. Por enquanto, esses pressupostos são provisórios e matizados por trânsitos. Ouvi a assistente social, um dos clínicos e algumas técnicas de enfermagem falarem dos efeitos da "preocupação" nos índices corporais. A primeira tem insistido que idosos que vivem sozinhos têm mais dificuldade de serem "pacientes controlados" porque não há ninguém para prolongar a coerção social iniciada pela equipe profissional. Ou mesmo as pessoas que frequentam a instituição reforçam que o "nervoso" só pode ser eficientemente "controlado" pelos medicamentos alopáticos, como me disse D. Leonice. E mesmo que o grupo de apoio não ofereça o que seu nome sugere, percebo que as pessoas aproveitam o fato de estarem juntas ali no mesmo espaço algumas vezes por ano. Nos bancos de espera, no caminho entre vir e voltar do centro de saúde e também no grupo de ginástica, há trocas de receitas, perguntas sobre o bem estar alheio, sugestões para se resolver os conflitos enfrentados dentro de casa. Outras linhas de apoio, talvez menos institucionais, são lançadas e amarradas entre esses pacientes, ao longo do tempo oferecido no convívio com uma doença crônica, muito do qual passado dentro do Centro e suas imediações. 
Além disso, percebo como estes pacientes crônicos, há tempos convivendo com essas doenças, têm se assemelhado aos "expert patients" descritos por Bury (1982), mas não apenas porque conhecem, a partir da própria experiência, a doença em questão, mas também porque conhecem como navegar pelos vários espaços onde essas doenças são discutidas. Vão se tornando bilíngues da cronicidade, no sentido de conseguirem navegar pelos pressupostos biomédicos e também pelos modelos explicativos populares que encontram em casa, na rua, no trabalho e pelos espaços não oficiais do Centro. No consultório, falarão do "medicamento que precisa ser trocado", nos bancos de espera, falarão do "aperreio causado pelo desemprego" e ambos os quadros descritos levarão ao entendimento de uma pressão repentinamente alta naquela manhã. $\mathrm{O}$ adoecido crônico bilíngue não fala de desemprego no consultório e nem vice-versa, sabendo da maior eficácia da linguagem adaptada.

Infelizmente, esta experiência acumulada, esse bilinguismo da cronicidade, é pouco valorizado pela equipe e por isso, a meu ver, os rituais de medição nas salas de acolhimento ou nos grupos de apoio são tão silenciosos. A experiência do adoecido não é vista como um "saber" e, portanto, não é digna de ser compartilhada e virar mote de um diálogo. Ao mesmo tempo, há uma supervalorização do "controle" como tecnologia oferecida, até de forma dadivosa, pela equipe. No final das contas, apenas seguem o que é preconizado pelas diretrizes do Ministério da Saúde, mas veiculam esses serviços pela potente e concentrada ideia do "controle do hipertenso e do diabético", como se estivessem oferecendo algo personalizado a cada paciente. O adoecido, portanto, é enredado duplamente nessa malha, afinal, se não seguir as prescrições médicas, passa a ser visto como um "paciente relaxado" pela equipe e, se não reconhecer a oferta de algo tão especial por esta última, infringe em uma desfeita moral e receberá ainda menos cuidado da mesma. Acredito que conhecer melhor os "modelos explicativos" de todos os atores envolvidos no cuidado da hipertensão e da diabetes, tanto em suas atuações nos espaços institucionais quanto nos menos hegemônicos e oficiais, permitirá aflorar os saberes e fazeres no trato cotidiano dessas complexas doenças e, mais importante, reconhecer que, sim, há um acúmulo de aprendizados que pode ser útil para desenhar políticas de saúde mais compreensivas.

Só depois de alguns meses de convivência ali no Centro atentei-me para uma nuance terminológica. A equipe profissional se refere ao conjunto de pessoas que se reúnem tri ou quadrimestralmente como "grupo de apoio". Mas os adoecidos, especialmente com hipertensão, chamam esse coletivo de "grupo da pressão". Claro, essa última acepção se remete à hipertensão arterial sistêmica, mais conhecida por ali como "problema de pressão". No entanto, mais importante a meu ver, é uma alusão discreta e um pouco irônica à pressão realizada naquele espaço, ao "controle" exercido em tantas salas, por tantos agentes do SUS, em tantos momentos do 
tratamento continuado de uma doença crônica. A meu ver, o uso desse segundo termo, o "grupo da pressão", reforça a meu ver a diferença entre os três pressupostos que delineei acima, a saber, o tempo presente (face ao tempo passado ou futuro), à externalidade causal (face à internalidade causal) e ao cenário social e integrado (face fragmentação ou atomização da doença) que norteiam o manuseio destas duas doenças crônicas. Chamar de grupo “de pressão" e não "de apoio" parece indicar a forma como se concebe e se controla, ou melhor, como repetem sempre meus interlocutores, se cuida dessas doenças na Guariroba. As pessoas notam com facilidade inúmeras práticas de controle ali realizadas. Identificam a "pressão" (o "controle") e até reproduzem este princípio, mas à sua moda. Percebem essa tendência de patologizar as condições de vida, as preocupações, as emoções, mas a medicalização não é totalmente a forma como manejam suas doenças ou distúrbios.

\section{AGRADECIMENTOS}

Agradeço aos ricos comentários e sugestões que esse artigo recebeu, em suas diferentes versões rascunhadas, dos participantes do Grupo de Estudos de Antropologia da Saúde, coordenado por Silvia Guimarães, Carla Teixeira e eu e do "Seminário Clínico: A Psicopatologia e suas interfaces", coordenado por Valeska Zanello, ambos da Universidade de Brasília, e do Grupo de Trabalho "Saúde, emoção e moral", coordenado por Cynthia Sarti e Maria Claudia Coelho, no $36^{\circ}$ Encontro Anual da ANPOCS, de 2012.

\section{NOTAS}

1 “O HIPERDIA é um Sistema de Cadastramento e Acompanhamento de Hipertensos e Diabéticos captados no Plano Nacional de Reorganização da Atenção à hipertensão arterial e ao Diabetes Mellitus, em todas as unidades ambulatoriais do Sistema Único de Saúde, gerando informações para os gerentes locais, gestores das secretarias municipais, estaduais e Ministério da Saúde. Além do cadastro, o Sistema permite o acompanhamento, a garantia do recebimento dos medicamentos prescritos, ao mesmo tempo que, a médio prazo, poderá ser definido o perfil epidemiológico desta população, e o consequente desencadeamento de estratégias de saúde pública que levarão à modificação do quadro atual, a melhoria da qualidade de vida dessas pessoas e a redução do custo social". http://portal.saude.gov.br/portal/se/datasus/area. cfm?id_area=807. Acesso em 02/09/2012.

2 À época, a equipe ainda utilizava os prontuários em papel. No último ano, a Secretaria de Estado de Saúde do Distrito Federal (SES/DF) tem informatizado os prontuários e assim resta saber como isso tem repercutido no ritual do grupo de apoio mais atualmente.

${ }^{3}$ Ao contrário de simplesmente organizar o atendimento por ordem de chegada, a equipe tem priorizado a longevidade dos pacientes. Os mais idosos são atendidos em primeiro lugar e, assim, os prontuários eram organizados conforme o ano de nascimento.

${ }^{4}$ A "Sociedade de Habitação de Interesse Social" (SHIS), um dos primeiros órgãos de execução da política habitacional do Distrito Federal, ainda nos anos 1970 e 1980, construiu e distribuiu a preços subsidiados, casas e lotes para famílias de baixa renda que haviam chegado à cidade.

${ }^{5}$ Aproveito para agradecer a Gustavo Angeli, Natalia Bezerra, Natharry Almeida, 
Polliana Esmeralda, Monique Batista e Hugo Cardoso que têm trabalhando comigo nos últimos anos e me ensinado muito a partir de sua perspectiva como pesquisadores aprendizes. Agradeço também às pessoas e famílias que têm se disposto a nos receber para um dedo de prosa sobre temas tão corriqueiros e, por vezes, desimportantes para eles. Somos gratos também ao Centro de saúde em questão, bem como ao Departamento de Antropologia, ao Decanato de Ensino e Graduação, e ao Decanato de Extensão da Universidade de Brasília que têm nos apoiado, entre outras coisas, com bolsas de pesquisa.

${ }^{6}$ Diariamente, no início da manhã, um professor ligado à Secretaria de Estado de Educação, oferece aulas de ginástica a um conjunto de idosos do bairro. Muitas dessas pessoas também têm hipertensão e/ou diabetes, são pacientes deste Centro de saúde bem como habitués do grupo de apoio.

7 Agradeço à Maria Claudia Coelho por esse ótimo insight a partir de meus dados de pesquisa.

${ }^{8}$ Ouvi muitas vezes a menção aos psicotrópicos - prescritos ou autoprescritos - para resolver "problemas de pressão" e talvez estejamos diante de uma psiquiatrização da hipertensão, tema muito instigante para mais pesquisas.

${ }^{9}$ A interpretação dos serviços públicos como uma dádiva maussiana já foi realizada por outros pesquisadores (Machado 2003; Cohn 2009) e certamente merecerá mais atenção de minha parte em escritos futuros.

\section{REFERÊNCIAS}

Becker, G. 1997. Disrupted lives: How people create meaning in a chaotic world. Los Angeles e Berkeley: University of California Press.

Bezerra, N. 2011. Bombinha, reloginho ou pera:
O uso de equipamentos biomédicos no cuidado da saúde de pessoas vivendo com hipertensão e diabetes na Guariroba, Ceilândia, DF. Trabalho de Conclusão de Curso. Graduação em Bacharelado em Antropologia, Universidade de Brasília, Brasília, Brasil.

Bezerra, N. \& S. Fleischer. s/d. A popularização de esfigmomanômetros e glicosímetros no bairro da Guariroba, Ceilândia/ DF. No prelo.

Bury, M. 1982. Chronic illness as biographical disruption. Sociology of Health and Illness 5: 168-195.

Calvo-Gonzalez, E. 2011. Construindo corpos nas consultas médicas: uma etnografia sobre Hipertensão Arterial em Salvador, Bahia. Cadernos CRH 24(61): pp. 81-96.

Canesqui, A. M. 2007. Estudos socioantropológicos sobre os adoecidos crônicos, in Olhares socioantropológicos sobre os adoecidos crônicos. Editado por A. M. Canesqui, pp. 19-51. São Paulo: Hucitec/FAPESP.

Cohn, A. (org.). 2009. Saúde da família e SUS: convergências e dissonâncias. Rio de Janeiro: Beco do Azougue/Fundação Ford; São Paulo: Cedec.

Conrad, P. 1990. Qualitative research on chronic illness: A commentary on method and conceptual development. Social Science \& Medicine 30(11): 1257-1263.

Conrad, P. \& M. Bury. 1997. Anselm Strauss and the sociological study of chronic illness: A reflection and appreciation. Sociology of Health \& Illness 19(3): 373-376.

Corbin, J. \& A. Strauss. 1985. Managing chronic illness at home: Three lines of work. Qualitative Sociology 8(3): 224-247.

Fleischer, S. 2010. A cronicidade e o controle: notas etnográficas sobre pessoas com hipertensão e diabetes num bairro da Ceilândia Sul, DF. Comunicação apre- 
sentada na I Reunião de Antropologia e Politicas de Saúde, Universidade de São Carlos, 13/04/2010.

2012a. Uso e circulação de medicamentos em um bairro popular urbano na Ceilândia, DF. Saúde e Sociedade 21(2): 410-423.

2012b. O que acontece quando uma entrevista é devolvida à entrevistada? Notas sobre a construção do campo antropológico. Paper apresentado no XV Encontro de Ciências Sociais do Norte e Nordeste (CISO), Teresina, 47/set.

2012c. O mundo dos bem e mal passares: Vivendo com hipertensão na Guariroba, Ceilândia/DF. Revista Politica e Trabalho 37 ( ano XXIX): 149-164.

Fleischer, S., L. Rabello, M. Alvarenga, M. Batista, N. Almeida, P. Machado. 2012. É muito duro esse trabalho: Notas sobre um projeto de extensão em Antropologia. Revista Participação 21: 31-41.

Giddens, A. 1991. Modernity and self identity: Self and Society in the Late Modern Age. Cambridge: Polity Press.

Guell, C. 2011. Candi(e)d action: Biosocialities of Turkish Berliners living with diabetes. Medical Anthropology Quarterly 25(3): 377-394.

Kleinman, A. 1980. Patients and healers in the context of culture. An exploration of the borderline between anthropology, medicine and psychiatry. Berkeley: University of California Press.

Leibing, A. \& D. Groisman. 2004. Tão alto quanto o morro - Identidades localizadas de mulheres hipertensas na favela da Mangueira, in Tecnologias do corpo: Uma antropologia das medicinas no Brasil. Editado por A. Leibing, pp. 277-299. Rio de Janeiro: Nau Editora.

Machado, L. Z. 2003. Entre o inferno e o paraíso. Saúde, direitos e conflitualidades. Série Antropologia 342. Brasília, 20p.
Parsons, T. 1951. The social system. London: Routledge \& Kegan Paul.

Resende, M. L. S. 1985. Ceilândia em movimento. Dissertação de Mestrado. Departamento de Sociologia da Universidade de Brasília, Brasília.

Souza, M. L. P. de \& L. Garnelo. 2008. "É muito dificultoso!": etnografia dos cuidados a pacientes com hipertensão e/ou diabetes na atenção básica, em Manaus, Amazonas, Brasil". Cadernos de Saúde Pública 24(1): 91-99.

Taylor, D. \& M. Bury. 2007. Chronic illness, expert patients and care transition. Sociology of Health \& Illness 29(1): 27-45.

Tavares, B. 2012. Na quebrada, a parceria é mais forte: Jovens, vinculos afetivos e reconbecimento na periferia. São Paulo/Brasília: Annablume/Fundo de Apoio a Cultura do Distrito Federal.

Vigitel Brasil. 2008. Vigilancia de fatores de risco e proteção para doenças crônicas por inquérito telefônico. Série G. Estatística e Informação em Saúde. Brasília: Ministério da Saúde.

Recebido em 15/01/2013.

Aprovado em 17/03/2013. 